\title{
EL ESCENARIO BOLIVIANO EN 2018: ESTABILIDAD ECONÓMICA E INCERTIDUMBRE INSTITUCIONAL
}

\author{
Bolivia in 2018: Economic Stability and Institutional Uncertainty
}

\section{MARÍA TERESA ZEGADA CLAURE}

Universidad Mayor de San Simón, Bolivia

\begin{abstract}
RESUMEN
La coyuntura boliviana durante el 2018 estuvo marcada por un panorama económico estable, aunque en declive y con signos de deterioro hacia el futuro; no obstante, el partido de gobierno destacó la estabilidad como uno de sus principales logros y como emblema hacia las próximas elecciones generales de 2019. Un aspecto crítico de la democracia boliviana, que se reveló de manera incontrastable durante el año, fue la profunda crisis de su institucionalidad, reflejada fundamentalmente en la crisis de credibilidad en el Órgano Electoral Plurinacional y la decisión del gobierno de insistir en la postulación del actual presidente como candidato a los próximos comicios, frente a la protesta ciudadana por la defensa del resultado del referendo de 2016, generando un clima de conflictividad.
\end{abstract}

Palabras clave: democracia, repostulación, Evo Morales, crisis institucional, estabilidad

\begin{abstract}
The year 2018 was marked by a stable economic panorama, albeit one with signs of decline and deterioration extending into the near future. However, the governing party highlights stability as one of its main achievements as it looks toward the next general elections of 2019. A critical aspect of Bolivian democracy, underscored yet again during 2018, was institutional crisis. This was mainly reflected in the crisis of credibility of the Organo Electoral Plurinacional and the government's insistence on supporting Evo Morales as a presidential candidate yet again, despite public protest in defense of the result of the 2016 Referendum, generating a climate of conflict.
\end{abstract}

Key words: Democracy, Reelections, Evo Morales, Institutional Crisis, Stability 


\section{INTRODUCCIÓN}

El inicio de 2018 estuvo marcado, en Bolivia, por intensos conflictos sociales, quizás los más conflictivos del último mandato del presidente Morales. Se aglutinaron problemas gremiales en rechazo a determinadas políticas públicas y decisiones estatales, el malestar ciudadano respecto a la aprobación de un Código Penal que afectaba diversos intereses y una demanda instalada en el campo político de respeto al voto ciudadano del referendo realizado el 21 de febrero de 2016, en el cual la población expresó un mayoritario rechazo a una reforma constitucional que permitía la repostulación del actual presidente. El año 2018 también ha sido relevante en la agenda política internacional por los acontecimientos que rodearon la resolución de la Corte Internacional de La Haya respecto al tema marítimo y las controversias entre Bolivia y Chile, cuya sentencia fue emitida, justamente, en octubre de 2018, generando un ambiente de preocupación en el Estado y de desánimo en los diferentes segmentos de la sociedad boliviana.

Durante el segundo semestre, el hecho relevante en el ámbito político fue la aprobación de la Ley de Organizaciones Políticas, que contempla la convocatoria a un proceso de elecciones primarias, inédito en la historia boliviana, que mueve las piezas del tablero político favoreciendo al actual partido de gobierno, pues consolida su interés particular en ratificar la candidatura de Morales y neutralizar a la oposición; al tiempo que sorprende a los partidos opositores, aún desarticulados y con escasa capacidad para generar alternativas políticas sólidas al actual gobierno.

Un factor relativamente invariable durante la gestión 2018 ha sido el económico. El país ha logrado mantener cierta estabilidad y control sobre las variables macroeconómicas generando un clima de confianza; aunque algunas medidas, como la reposición del doble aguinaldo, han generado reacciones adversas por el daño colateral a sectores empresariales pequeños y medianos. Además, fue percibida por la población como parte de una campaña electoral adelantada.

El año culmina con una sombra de incertidumbre sobre el próximo proceso electoral de octubre de 2019 y el agravamiento de la crisis institucional, en particular del Órgano Electoral Plurinacional, por su actuación respecto a los resultados del referendo de 2016; la aceptación de la candidatura a las primarias del actual presidente Morales, vulnerando los resultados del pasado referendo; y la renuncia de varios vocales del Tribunal Supremo Electoral. 


\section{CRONOLOGÍA DE TEMAS RELEVANTES Y SU IMPACTO POLÍTICO}

\section{Coyuntura social}

\section{Rechazo social al Código Penal}

La gestión 2018 se inicia en medio de un gran conflicto social. Claro que el problema había comenzado a fines de noviembre de 2017, con una huelga del sector médico en rechazo a ciertos artículos de un proyecto de Código del Sistema Penal que se encontraba en plena fase de discusión y aprobación en la Asamblea Legislativa Plurinacional (ALP). Los profesionales médicos — luego se sumaron transportistas y otros sectores sociales- vieron afectados sus derechos en la futura legislación, por tanto, iniciaron un paro que tomó características de movilización en demanda de la anulación de algunos artículos del Código Penal. Se sumó entonces la ciudadanía, directa afectada por otras disposiciones que vulneraban sus derechos sociales y políticos. La demanda se fue ampliando hasta convertirse en un intenso ciclo de protestas que culminó con éxito a principios de 2018, pues logró la abrogación del nuevo Código del Sistema Penal. El conflicto sin duda asumió un carácter político, pues se conectó con las movilizaciones instaladas en el país en defensa de los resultados del referendo del 21 de febrero de 2016.

\section{Sectores sociales en conflicto}

Semanas más tarde se suscitó el conflicto, recurrente en cada gestión administrativa, entre la Central Obrera Boliviana (сов) y el gobierno por la aprobación del Presupuesto General de la Nación y la demanda de incremento de salarios. Durante mayo, en medio de una serie de enfrentamientos ocurridos en El Alto por la demanda de un mayor presupuesto universitario, se produjo la muerte Jonathan Quispe Vila, de veintiún años, estudiante de Comunicación Social de la Universidad Pública de El Alto (UPEA), que despertó la indignación ciudadana pues los responsables de su muerte fueron funcionarios de las fuerzas de seguridad del Estado que habían disparado "canicas" para desbaratar la movilización.

Otro de los conflictos recurrentes, que retomó fuerza en esta gestión, fue el ocurrido entre el gobierno y la Asociación Departamental de Productores de Coca de Los Yungas (ADEPCOCA), que tras varios enfrentamientos desarrollados entre julio y septiembre de 2018, dejó el saldo de tres muertos y varios heridos. Las discrepancias entre los cocaleros de la zona del Chapare de Cochabamba, lugar de donde proviene el líder del Movimiento al Socialismo (MAS), Evo Morales, y los cocaleros de los Yungas de La Paz, son históricas. En esta ocasión el enfrentamiento fue causado por desacuerdos en torno a la Ley General de la Hoja de Coca que, según los líderes de los Yungas, beneficiaba más al Chapare. 
El enfrentamiento se produjo por la toma del mercado de ADEPCOCA por grupos afines al gobierno y la lucha por su recuperación por parte de la dirigencia de los Yungas, así como en reacción a las campañas de erradicación de cocales en la zona de La Asunta.

Si bien estos conflictos se mantuvieron bajo control estatal y fueron finalmente resueltos, mostraron la actitud represiva del gobierno que, incluso, significó la pérdida de vidas humanas, y tuvo un impacto de desgaste en la imagen presidencial.

\section{La defensa a la democracia}

Emblemática fue la celebración de los treinta y seis años del retorno a la democracia el 10 de octubre de 2018, que se convirtió en un escenario para medir fuerzas entre el oficialismo y la oposición mediante movilizaciones en las calles de todos los departamentos del país. Mientras el mas proclamaba a Evo Morales como presidente, organizaciones sociales dirigidas por el Consejo Nacional de Defensa de la Democracia (CONADE), junto a las plataformas, conminaron al presidente a renunciar a la repostulación y exigieron al Tribunal Supremo Electoral (TSE) hacer respetar el voto del 21F. El vicepresidente Álvaro García Linera acusó a las plataformas ciudadanas de representar los intereses de la derecha. "No son Bolivia, no son el pueblo, no son futuro, ellos son simplemente el viejo pasado zombi, que no se ha dado cuenta que ya está muerto y que nunca va a poder resucitar", sostuvo (Opinión 2018, 10 de octubre).

Sin embargo, la consigna "Bolivia dijo no" se extendió durante todo el año y concentró la atención de la opinión pública nacional e internacional, mediante la movilización de residentes bolivianos en el exterior que han invadieron calles y eventos internacionales a los que Morales asistió para exigirle el respeto al voto.

En Bolivia, los activistas de "Bolivia dijo no" se hicieron presentes en escenarios oficialistas, como la celebración de aniversarios cívicos. Entre ellos, destacaron el evento protagonizado en agosto por Yuli Terrazas, una estudiante potosina que gritó "Bolivia dijo no" durante un acto cívico en presencia del presidente. También sucedió durante una sesión de honor por el aniversario de Cochabamba el 14 de septiembre, donde tras el grito "Bolivia dijo no", dos asambleístas departamentales opositoras fueron expulsadas a golpes y empujones por autoridades oficialistas tras interrumpir el discurso del vicepresidente Álvaro García Linera. Como último ejemplo lo sucedido en Potosí cuando Rafael Chambi, un joven albañil, fue aprehendido por la policía luego de gritar "Bolivia dijo no" al presidente Morales durante la celebración del aniversario de ese departamento.

Antes de culminar el año, los comités cívicos del país cerraron filas en rechazo a la candidatura de Morales y García Linera, asimismo se abrieron múltiples 
piquetes de huelga de hambre en distintos departamentos rechazando la decisión del TSE de aceptar la postulación del binomio oficialista a las primarias; sin embargo, estas movilizaciones se diluyeron entre las festividades de fin de año.

En síntesis, las protestas exigiendo el respeto al resultado del referendo del 21F fueron probablemente el principal factor de amenaza para el MAS en 2018. Su aparición durante el paro médico, los recurrentes bloqueos y movilizaciones junto a su presencia en la opinión pública, en particular a través de las redes sociales, fueron una característica persistente de este período.

\section{Plataformas y activismo ciudadano}

En medio de una profunda crisis de representación de la totalidad de partidos opositores del sistema y el agravamiento de la desconfianza en la política ${ }^{1}$, emergieron los denominados colectivos o activismos sociales en red (también ocupan espacios en las calles con medidas de protesta), articuladas a plataformas ciudadanas. Estas formas de acción política "ciudadanista" existen desde hace algunos años en la opinión pública y se caracterizan por interpelar a la sociedad con demandas propias de la vida cotidiana, despertando sensibilidad e indignación frente a algunos hechos de la realidad, como la violencia contra las mujeres, la vulneración de derechos de los animales, la depredación del medio ambiente, la coacción a la libertad de expresión, entre muchos otros. La mayoría de estos movimientos se sumó a la consigna política de defensa del voto del 21 de febrero mediante la convocatoria en las redes sociales a través de perfiles, grupos o páginas como "Bolivia dijo no", "generación 21F” y "No más Evo Morales", entre otras.

Lo anterior nos lleva a establecer que la política transita hoy por otros lugares, cuyo referente no corresponde al sistema de partidos ni las organizaciones gremiales y sindicales: ellos interpelan al ciudadano. La primera aparición masiva de estos activistas en la política nacional ocurrió durante el conflicto por el TIPNIS en 2011, concitando la atención internacional pues mereció la solidaridad ciudadana contra el Estado por el irrespeto a los derechos de los pueblos indígenas y los territorios protegidos.

Tapia (2008: 132) conceptualizó a estos movimientos, de características eminentemente sociales, como subsuelo político, definido como "aquel conjunto de prácticas y discursos políticos que no son reconocidos social y estatalmente pero emergen como forma de asociación, interacción y opinión sobre la dimensión política y de gobierno de las sociedades. El subsuelo político contiene crítica, desdén, ironía, sabotaje, parodia, en algunos casos formas alternas y alternativas" (Tapia 2008: 33). 
El activismo ciudadano en las calles y en redes sociales ha provocado una inmediata reacción del gobierno en dos direcciones: por una parte, movilizando a sus sectores de base a través de la Coordinadora Nacional para el Cambio (CONALCAM), instancia que aglutina a los sindicatos cocaleros, campesinos e interculturales y funcionarios públicos que sustentan al actual gobierno, mediante movilizaciones callejeras paralelas a las de los colectivos ciudadanos, tensionando el ambiente político e intentando neutralizar el impacto opositor; y, por otra, exhibiendo su capacidad de movilización popular. El gobierno ha iniciado, además, la denominada "guerra digital", para lo cual creó, en abril de 2016, la Dirección Nacional de Redes, entidad perteneciente al Ministerio de Comunicación, con el objetivo de "Desarrollar estrategias de difusión, consulta e interacción del gobierno del Estado con las cibercomunidades, mejorar las plataformas de información y comunicación de la gestión del Estado mediante la utilización de las redes sociales y promover la utilización de las redes sociales con la sociedad civil" (La Razón 2016, 26 de julio). La entonces ministra de Comunicación afirmó que se deseaba tener más presencia del gobierno en redes, identificar falsas identidades y mentiras o fake news. Para ello se destinó un presupuesto inicial de cinco millones de bolivianos. La entidad fue reforzada, más adelante, por otras estrategias (La Razón 2016, 3 de marzo).

Su trabajo consiste en crear perfiles - especialmente en Facebook, también en otras redes - que apoyan la gestión del presidente o discuten sobre temas políticos con usuarios comunes. Meses más tarde se creó un ejército compuesto por "soldados digitales", miles de jóvenes adiestrados para generar información tendiente a favorecer el posicionamiento gubernamental en redes sociales, junto a algunas medidas penales de coerción —desarrolladas sin éxito-contra los productores de memes de la oposición. La "guerra" también implicó un mayor involucramiento del propio presidente en su cuenta de Twitter, desde donde dispara mensajes para neutralizar o descalificar a la oposición.

Lo cierto es que estos escenarios de conflictividad social, propiciada por organizaciones sociales y activismos ciudadanos, han significado una permanente tensión para la estabilidad política del gobierno que intenta neutralizarlas, ya sea mediante el control de las organizaciones o bien a través de la descalificación ideológica, acusándolos de "derechistas" o funcionales al imperio estadounidense.

\section{Coyuntura económica}

De acuerdo con un informe del Banco Central de Bolivia, en el país se logró una orientación expansiva de la política monetaria. Según dicho informe,

la orientación se tradujo en la inyección de recursos para mantener niveles adecuados de la liquidez del sistema financiero y tasas de interés bajas, características que coadyuvaron a mantener el dinamismo del crédito. Complementariamente, se mantuvo la política de estabilidad del tipo de 
cambio, en el contexto de depreciación de la mayoría de las monedas de la región y contribuyó a conservar ancladas las expectativas del público sobre el valor del dólar, mantener la inflación importada controlada, profundizar el proceso de bolivianización y por tanto permitir una política monetaria expansiva (Banco Central de Bolivia 2019).

Se debe destacar que la orientación de la política cambiaria no ha generado modificaciones relevantes en el tipo de cambio real con relación a su equilibrio constante. Siguiendo el mismo informe, el Banco Central de Bolivia, junto al Órgano Ejecutivo, siguieron aportando al desarrollo económico y social del país a través de la creación de nuevas empresas estatales, créditos a las gobernaciones y municipios y transferencias a la población a través del pago de bonos.

En efecto, el crecimiento del Рів nacional hasta el tercer trimestre fue de 4,04 \%, que el gobierno destaca como uno de los más altos de Sudamérica.

Un análisis más crítico de la situación económica de 2018, basado también en cifras oficiales (Presupuesto General del Estado) como instrumento de política económica, muestra que, desde la llegada de Evo Morales a la presidencia se podrían establecer dos períodos: el primero desde 2006 hasta 2013 y el segundo desde 2014 hasta 2019. Durante los primeros ocho años se puede constatar que hubo un superávit fiscal acumulado de $14,5 \%$ respecto del PIB; en cambio, en los siguientes seis años (2014-2019) se cuenta con un déficit fiscal acumulado de $40 \%$ respecto del PIB, es decir, que en los últimos seis años hemos dejado de acumular y de ahorrar, a diferencia de los primeros ocho años, a lo que debemos añadir un gasto acumulado del 25,5\% respecto del рів. Todo ello muestra un panorama sombrío hacia el futuro.

El análisis también destaca una leve recuperación de los ingresos por exportaciones como efecto de la mejora en los precios internacionales de las materias primas, entre ellas, el petróleo, que de una previsión de 45,5 dólares el barril en el Presupuesto General del Estado, el año 2018 alcanzó a 70 dólares. El diagnóstico concluye, no obstante, que la economía boliviana sigue desacelerada.

Si bien el crecimiento económico es aceptable, su sostenibilidad es vulnerable por su alta dependencia de la exportación del gas hacia Argentina y Brasil, con contratos que vencen en los próximos años (con la Argentina el año 2026 y con Brasil el año 2019). Además, los yacimientos y la producción son limitados.

El mismo informe señala que durante el 2018 se registró un alto déficit fiscal, escaso ajuste en el gasto público y un mayor endeudamiento público que en anteriores gestiones. Concluye que existe una desaceleración de la inversión pública, junto a la clara declinación de la producción hidrocarburífera y una inversión privada que se dirime entre la parálisis y el retroceso. Esto ha generado cierta preocupación por la situación macroeconómica del país y una previsión pesimista respecto a los próximos años por parte de los agentes económicos. 
Sin embargo, también se hace notar que la política económica del gobierno, pese a la desaceleración y caída de ingresos de los últimos años, no ha cambiado, pues continúa con medidas de expansión del gasto público financiado con "desahorro" y endeudamiento público para que continúe el crecimiento económico, optando por el extractivismo, es decir, una mayor explotación de recursos naturales, la venta de electricidad y el desarrollo del turismo.

De acuerdo con datos oficiales, las cifras de crecimiento económico y tasa de inflación esperada para el 2018 eran de 4,7 \% y 2,79 \%, respectivamente, con un déficit fiscal respecto del PIв de $8,32 \%$ y un déficit de balanza comercial respecto del PIB de 0,9\%. El informe crítico publicado en ANF concluye que persisten los desequilibrios internos tanto como externos, y que se avecina una situación de crisis irremediable (Molina Díaz 2018, 30 de diciembre). A pesar de esta situación, a fines de 2018 el gobierno decidió reponer la medida del doble aguinaldo (decisión basada en la cifra de crecimiento superior al 4 \%), con la cual generó un clima de satisfacción en los asalariados, pero una gran preocupación en las empresas privadas, en particular las pequeñas y medianas, que tuvieron que despedir personal o, en algunos casos, declarar su cierre definitivo.

\section{Coyuntura internacional}

Desde el inicio del año 2018, la opinión pública nacional estuvo fuertemente impregnada por la acción que el gobierno boliviano había emprendido tiempo atrás en la Corte Internacional de Justicia de La Haya respecto a la controversia del mar con Chile. Durante los primeros meses se realizaron los alegatos orales tanto de Chile como de Bolivia, que fueron seguidos por la opinión pública nacional con gran expectativa y optimismo. La resolución a dicha situación fue anunciada por la instancia jurídica internacional el día 1 de octubre, rechazando los términos de la demanda planteada por Bolivia, lo cual significó un duro golpe para la comisión encargada y para el Estado boliviano, estableciendo la no obligatoriedad para Chile de negociar este tema con el país. Sin embargo, los magistrados dejaron abierta una leve posibilidad de diálogo, pues entre sus conclusiones generales señalaron que el fallo "no debe impedir que las partes continúen su diálogo e intercambios en un espíritu de buena vecindad".

La resolución significó en los hechos el cierre de expectativas sobre el tema y un duro golpe para el gobierno, que había depositado sus expectativas en la negociación. La población también percibió la derrota. Una encuesta realizada en las principales ciudades del país - La Paz, El Alto, Cochabamba y Santa Cruz - publicada en la prensa, mostró que más del $70 \%$ de la población tenía la percepción de que el fallo de La Haya había sido incorrecto, al mismo tiempo que repartía responsabilidades del fallo negativo entre varios líderes, de manera prioritaria al gobierno de Morales. En la misma encuesta, un 93 \% expresó que, a partir de la experiencia en La Haya, Bolivia debería replantear su manejo diplomático y un 80 \% planteó mantener la esperanza y creer que el país 
aún tiene alternativas para acceder a una salida al mar. Respecto de la política interna, la encuesta reveló que el 49 \% de las personas creía que el fallo sobre la demanda marítima emitido por la Corte Internacional de Justicia (cIJ) influía contra las intenciones de repostulación del presidente Evo Morales².

De alguna manera esta encuesta refleja el sentimiento nacional y al mismo tiempo la derrota política del gobierno de Morales o, al menos, la dificultad para utilizar a su favor este resultado en una futura campaña electoral.

\section{GESTIÓN POLÍTICO-INSTITUCIONAL}

\section{Los órganos del Estado boliviano: Ejecutivo, Legislativo, Judicial y Electoral}

En Bolivia, de acuerdo con la Constitución Política del Estado, se cuenta con cuatro órganos: el Ejecutivo, el Legislativo, el Judicial y el Electoral.

En relación con el Ejecutivo, en 2018 no reporta grandes novedades; de hecho, al inicio de la gestión se posesionó al gabinete, como sucede todos los años, y prácticamente todos los ministros y ministras fueron ratificados excepto dos autoridades que fueron reemplazadas: en el cargo de ministro de la Presidencia fue posesionado Alfredo Rada, mientras que en el Ministerio de Defensa asumió Javier Zavaleta.

Respecto al Legislativo, la mayoría de más de dos tercios que ostenta el partido de gobierno en la Asamblea Legislativa Plurinacional permite una aprobación fluida de leyes. En la gestión 2018-2019, por ejemplo, se aprobaron ciento veintiún leyes. Por su parte, la presencia opositora es prácticamente testimonial. En el caso del Órgano Judicial, se inició el año con la posesión de las nuevas autoridades recién electas para un lapso de seis años mediante comicios generales realizados a fines de 2017. El presidente del Estado posesionó a nueve magistrados titulares y suplentes del Tribunal Supremo de Justicia, a nueve titulares y suplentes del Tribunal Constitucional Plurinacional, a cinco titulares y suplentes del Tribunal Agroambiental, junto a tres titulares y suplentes del Consejo de la Magistratura.

El órgano que generó mayor impacto en el sistema político boliviano durante la gestión 2018 fue el Órgano Electoral Plurinacional, por varias razones que analizamos a continuación.

Es este órgano la máxima autoridad en Bolivia sobre temas electorales. Su composición se define en el seno de la Asamblea Legislativa Plurinacional. Sin duda, al ser la ALP una instancia eminentemente política y, en este caso,

2 Encuesta realizada por Ciesmori el 4 y 5 de octubre y publicada en el periódico Los Tiempos (Vásquez 2018, 7 de octubre). 
dominada de forma mayoritaria por representantes del partido de gobierno, existe una incidencia política clara en la conformación de esta instancia electoral.

\section{Tensiones políticas entre órganos del Estado}

Este último órgano enfrentó, en febrero de 2016, uno de los retos más importantes de su gestión: administrar el referendo que, a iniciativa de legisladores del partido de gobierno, proponía la modificación de un artículo de la Constitución Política del Estado que impedía a Evo Morales la repostulación, una vez más, como candidato a la presidencia.

En dicho referendo se consultó a los ciudadanos: “¿Usted está de acuerdo con la reforma del artículo 168 de la Constitución Política del Estado para que la Presidenta o Presidente y la Vicepresidenta o Vicepresidente del Estado puedan ser reelectas o reelectos por dos veces de manera continua? Por Disposición Transitoria de la Ley de Reforma Parcial a la Constitución Política del Estado, se considera como primera reelección al período 2015-2020 y la segunda reelección el 2020-2025".

Los resultados de dicha votación demostraron que una mayoría de bolivianos, concretamente el $51.3 \%$, que significan 2.682 .517 votantes, rechazaba la modificación de la Constitución, mientras que el sí, es decir, el apoyo a la modificación para la repostulación, alcanzó el 48.7 \%, que representa un total de 2.546.135 votos. El triunfo del no fue notable en los departamentos del oriente, tradicionalmente opositores al gobierno, a los que se sumaron Potosí y Chuquisaca, mientras en los departamentos de occidente, vale decir La Paz, Cochabamba y Oruro, se impuso el apoyo a la reelección de Morales. Con estos resultados se negaba legalmente la posibilidad de la repostulación de Morales para las próximas elecciones de 2019.

El evento electoral se produjo en medio de una alta polémica propiciada fundamentalmente por dos antecedentes: el destape de la corrupción del Fondo Indígena, que involucraba a varios sectores campesinos vinculados al gobierno; y una denuncia contra el presidente del Estado por vínculos con Gabriela Zapata, la supuesta madre de un hijo y expareja de Morales, que se benefició de manera ilícita con cuantiosas sumas de dinero por contratos con el Estado. Esta última denuncia surgió dos semanas antes del evento electoral. Según la lectura del MAs, este escándalo público habría afectado negativamente en los resultados del referendo, acusando a la oposición de haber generado una estrategia basada en la falsedad de los hechos e insistiendo en que se trató de un acto de manipulación mediática y de la viralización de "la mentira" en las redes sociales, argumento con el cual intentaron desestimar los resultados.

Más adelante, con el fin de ensayar otra estrategia que garantice la repostulación de Morales, en septiembre de 2017 un grupo de legisladores del mas presentó una acción de inconstitucionalidad abstracta al Tribunal Constitucional 
Plurinacional, instancia que dos meses después, el 28 de noviembre de 2017, emitió un fallo favorable a la petición del partido de gobierno, días antes de la conclusión del mandato de los magistrados judiciales de dicho tribunal. Así, la sentencia constitucional 0084/2017 definió la habilitación del presidente Evo Morales, al vicepresidente Álvaro García Linera (junto a todas las autoridades electas a nivel nacional y subnacional) a repostularse a los cargos en ejercicio, puesto que según el argumento esgrimido por los miembros del TCP, la sentencia constitucional 0084 se basaba en la aplicación preferente del artículo 23 de la Convención Americana de Derechos Humanos (CADH) por ser una norma más favorable que los derechos políticos sobre los artículos 156, 168, 285 y 288 de la Constitución Política del Estado (CPE), que limitaban la reelección continua de los gobernantes. El TCP argumentó que la medida restrictiva era limitante al ejercicio de los derechos políticos (la repostulación) y resultaba innecesaria, pues la eventual repostulación representaba solo una posibilidad y no garantizaba, de modo alguno, que el que ejerce el cargo vaya a ser elegido o reelecto por decisión del voto de los ciudadanos. En paralelo, más de treinta organizaciones afines al mAs presentaron adhesiones al recurso de inconstitucionalidad, en medio de fuertes tensiones políticas y una dura crítica a los magistrados que cumplían sus últimos días de mandato. A pesar de que el fallo fue positivo, se desencadenó una ola de cuestionamientos desde la sociedad civil que pusieron en duda la idoneidad de los jueces salientes y la validez del fallo que, según el gobierno, era vinculante y tenía supremacía frente al voto del referendo.

Estos antecedentes tensionaron al Órgano Electoral Plurinacional durante el año 2018, por una parte, por la fuerte presión ciudadana que exigió el respeto al voto bajo la consigna "Bolivia dijo no" y, por otra, por la presión del partido de gobierno a través de su insistencia en repostular al actual presidente del Estado.

En todo caso, el 2018 brindó una nueva oportunidad para sellar la repostulación del binomio oficialista, mediante la aprobación de una Ley de Organizaciones Políticas No. 1096 que sustituía la antigua Ley de Partidos Políticos de 1999. La ley venía discutiéndose durante los últimos seis años, pues respondía a la necesidad de del sistema representativo de adecuarse a los preceptos de la Constitución Política del Estado aprobada en 2009.

El problema se suscitó entre el Legislativo y el Electoral, pues la propuesta de ley presentada por el OEP en junio de 2018 ante la Asamblea Legislativa Plurinacional con la idea de continuar con discusión y los ajustes correspondientes, de manera intempestiva fue modificada y aprobada en el seno de la Asamblea Legislativa Plurinacional, sin consultar a los vocales del Órgano Electoral. Ella fue inmediatamente promulgada por el presidente del Estado, el 1 de septiembre de 2018.

Es preciso detenernos en las características de esta ley, en particular en sus modificaciones, puesto que son piezas claves para comprender el alcance de la crisis del TSE y la capacidad del partido de gobierno para consagrar la anhelada repostulación. 
No cabe duda de que el contenido de la nueva Ley de Organizaciones Políticas 1096 está orientado a la profundización de la democracia interna en las organizaciones políticas ${ }^{3}$ y su adecuación a los principios de la democracia intercultural y paritaria. Entre otras disposiciones novedosas, se insertan las sanciones al acoso y la violencia política contra las mujeres, la clarificación de la noción de transfugio político y sus respectivas sanciones, se establece una mayor participación para los jóvenes y la paridad y alternancia para las mujeres, así como la preservación de la democracia ejercida en organizaciones indígenas originarias y campesinas. Del mismo modo se recupera el financiamiento público para las organizaciones políticas (OP), suspendido en 2008, bajo la modalidad de financiamiento mixto en campañas y en etapas no electorales, mediante subvenciones indirectas en publicidad y capacitación buscando velar por la equidad en la competencia política y mayores derechos para los militantes. Finalmente se ratifica la necesidad de adoptar mecanismos de democracia interna, tanto en la toma de decisiones como en la conformación de las estructuras internas y la selección de candidaturas.

Ahora bien, respecto a esto último, en la misma ley se introduce la disposición concreta sobre las elecciones primarias internas como mecanismo para la selección de binomios presidenciales. Esta disposición, pensada como parte de las anteriores reformas, fue tomada por el partido de gobierno como instrumento para garantizar la consolidación del binomio Morales-García Linera, en consecuencia, una vez que la propuesta fue entregada a la ALP se modificaron justamente aquellos aspectos referidos a su inmediata aplicación.

De esta forma, la modificación a la Ley de Organizaciones Políticas en el seno de la ALP se centra en el cierre de plazos para la aplicación inmediata de las elecciones primarias. La propuesta de ley enviada por el oEP había previsto la aplicación de las primarias de manera progresiva hasta 2024. Como todos conocemos, las disposiciones específicas de una ley —en este caso, los plazos- son objeto de una reglamentación, sin embargo, fueron cerrados en la ALP tanto en los artículos concernientes de la ley a las primarias y, en los artículos transitorios, fijando un apretado y obligatorio cronograma al que debían someterse las op que pretendían habilitarse para las elecciones generales de octubre de 2019.

Estas modificaciones se contradicen con algunos principios establecidos previamente en la misma ley como, por ejemplo, permitir a las organizaciones políticas que adopten sus propias instancias y mecanismos de toma de decisiones y selección de dirigentes y candidatos de acuerdo a cada estatuto orgánico, no obstante la legislación sobre las primarias (artículo 29) establece este mecanismo como procedimiento único, homogéneo y obligatorio, así como simultáneo para todas las op, fijando como fecha de elección el día 27 de enero de 2019. Sin embargo, el aspecto más crítico de esta norma está establecido en el

Nominación genérica utilizada en la CPE de 2009 para abarcar a tres tipos de actores políticos con capacidad representativa: partidos políticos, agrupaciones ciudadanas y organizaciones de pueblos indígenas originarios y campesinos. 
inciso XII del mismo artículo 29, que se señala que los resultados de las primarias serán vinculantes a la elección general de octubre de 2019: "Los resultados de la elección de candidaturas de binomio presidencial, serán vinculantes y de cumplimiento obligatorio para los partidos o alianzas y para las elecciones generales. Las únicas causales que pueden revertir el carácter vinculante de estos resultados son la muerte o una enfermedad gravísima sobreviniente debidamente comprobada de alguna o alguno de los miembros del binomio elegido". La disposición inhibe la posibilidad de que algún candidato desista a su postulación para aliarse o apoyar a otro en aras a la anhelada unificación que buscaban los opositores.

Estas disposiciones de la LoP respecto de las primarias conducen a un escenario desigual para las organizaciones políticas, pues facilitan al MAS-IPSP la consolidación prematura del binomio (sin lugar a que se pueda volver a debatir esta situación) y porque prácticamente era el único partido que cumplía con todos los requisitos y contaba con un binomio definido; mientras que las otras organizaciones políticas opositoras, en condiciones adversas respecto al tiempo, apenas comenzaban a perfilar algunos posibles candidatos "sin partido"; tampoco pudieron generar alianzas, como era el propósito inicial, para enfrentar con mayores posibilidades al binomio oficialista.

Estos cambios en la normativa sin consulta a la entidad electoral que había elaborado la propuesta de ley, generaron una fuerte tensión entre órganos del Estado y la renuncia de tres de los siete vocales electorales nacionales: primero, de uno de los vocales, José Luis Exeni, seguido de la presidenta de esa entidad, Kathia Uriona y, finalmente, de la tercera vocal Dunia Sandoval, debilitando sustancialmente a la entidad y provocándole una severa crisis interna, sumada a su ya deteriorada imagen ante la opinión pública nacional.

\section{COYUNTURA POLÍTICA MARCADA POR LAS ELECCIONES PRIMARIAS}

Los partidos siempre han sido vistos con cierta desconfianza por la sociedad civil, en consecuencia, han tenido una débil presencia como instancias mediadoras eficaces en la historia de Bolivia. Como sostiene Zovatto (2011: 45), los partidos, como instituciones, tienen una falla de origen en la historia política, pues su aparición estuvo acompañada de desconfianza y rechazo por parte de la población tanto en Europa como en América Latina, que fue mejorando con la conquista social de derechos políticos. Los momentos más críticos en cuanto transformaciones sociales en Bolivia, como la revolución nacional o la reconquista de la democracia, así como la crisis y transformaciones de principios de este siglo, fueron protagonizadas por organizaciones de la sociedad civil o movimiento sociales que lograron articular a la sociedad detrás de demandas estructurales cuestionando las bases políticas del Estado. En unos casos fue la histórica presencia de la Central Obrera Boliviana; en otros, 
los sindicatos campesinos o los movimientos indígenas y, en las última década, el activismo ciudadano, que logró mayores adhesiones espontáneas que los partidos políticos.

La aprobación de la mencionada Ley de Organizaciones Políticas precipitó el cronograma de ejecución. Después de otorgar unas cuantas semanas para su habilitación, los partidos lograron —con dificultad-cumplir con los requisitos establecidos en la ley, de ahí que nueve organizaciones políticas, de más de veinte que comenzaron el proceso, llegaron a habilitarse. Estas son: Movimiento al Socialismo (MAs), Alianza "Bolivia dice no" (BDN), Frente para la Victoria (FPV), Frente Revolucionario de Izquierda (FRI) y, lanzado como Comunidad Ciudadana en alianza con plataformas, el Movimiento Demócrata Social (Demócratas) en la Alianza "Bolivia dice no", Movimiento Nacionalista Revolucionario (MNR), Partido de la Acción Nacional Boliviano (PAN-BOL), Partido Demócrata Cristiano (PDC) y Unidad Cívica Solidaridad (UCS).

Uno de los problemas críticos en este proceso de habilitación se produjo al momento del registro de militantes, porque todas ellas se vieron ante el desafío de abrir sus libros de inscripción en un apresurado proceso de reclutamiento para cumplir con los requisitos de la norma. El MAs, si bien ya contaba con el número mínimo de militantes exigido, asumió dicha tarea para engrosar las filas del partido y, como señaló el propio vicepresidente del Estado, para mostrar su "musculatura política" desplegando una intensa campaña para inscripción de militantes nuevos a través de los sindicatos campesinos que lo sustentan y cuya estructura tiene presencia en todo el territorio nacional.

Esta situación de apresuramiento generó varias irregularidades en la inscripción de militantes, pues comenzaron a surgir una serie de denuncias respecto a registros de militantes "falsos" o libros "inflados", junto a errores en el proceso de registro. El tema generó mucha polémica en la opinión pública por la gran cantidad de denuncias de ciudadanos que negaban haberse inscrito en alguna op, lo cual llevó a líderes de partidos opositores a rechazar la realización de las primarias por falta de un padrón confiable de militantes. El TSE habilitó una aplicación en la página web denominada "Yo participo", con el fin de que la ciudadanía pueda consultar su registro y permitirle, al mismo tiempo, llenar un formulario para renunciar a su condición de militante si esta no había sido autorizada.

Una mirada rápida a los datos sobre los militantes inscritos permite establecer algunas conclusiones sobre el actual sistema de partidos boliviano. El primero es que, de un padrón electoral de un total de 6463256 personas, 1715 .880 están registradas en alguna organización política, es decir, el 26,5\% pertenece hoy a alguna op. El segundo dato es que el MAs corresponde al partido que cuenta con una mayor militancia (el 57,7 \% del total de militantes registrados en el país), seguido de 21F (que es el frente constituido con base en el partido Movimiento Demócrata Social), que cuenta con el $17 \%$ de los militantes, mientras los demás partidos no trascienden el $6 \%$ del total nacional. 
Tabla 1. Militantes por organización política en Bolivia

\begin{tabular}{lr}
\hline \multicolumn{1}{c}{ Organización POlítica } & Militantes \\
\hline PDC & 28717 \\
FPV & 31060 \\
UCS & 38421 \\
MNR & 58377 \\
CC & 88122 \\
PAN-BOL & 92210 \\
MTS & 95391 \\
21F & 292490 \\
MAS-IPSP & 991092 \\
\hline Total & 1715880 \\
\hline
\end{tabular}

Fuente: elaboración propia con base en datos del oEP

En el caso del MAs, el gran tamaño de su padrón de militantes responde a varios factores. Por una parte, se debe a su permanencia en el poder por doce años consecutivos; por otra, al liderazgo populista de Evo Morales, que cuenta con un peso propio debido a su trayectoria y carisma personal. No obstante, el factor central es su base social sindical, que forma parte de la propia organización política. La estructura del MAs es atípica porque, lejos de ser un partido tradicional, es una organización fuertemente anclada en organizaciones sindicales campesinas, por ello ha sido definido como un "movimiento político" más que como un partido (Komadina-Geffroy 2012: 14). Ello explica su expansión territorial y su capacidad organizativa, pues está presente en todos los departamentos y municipios del país, y también demuestra la organicidad con que actúan los integrantes del partido-sindicato.

Los datos respecto al registro de militantes también muestran la profunda crisis de la categoría de "militancia política" en el país (Zegada 2017: 27), en algunos casos sustituida por bases sindicales orgánicas como en el MAS, en otros por la presencia circunstancial y volátil de adherentes sin un compromiso orgánico e ideológico.

Para concluir este análisis abordaremos brevemente las características de esta primera experiencia de primarias obligatorias, simultáneas y cerradas en Bolivia, desarrollada el 27 de enero de 2019.

Fue esta la primera vez que en Bolivia se realizó una elección de esta naturaleza, por tanto, hubo desinformación y apatía ciudadana. Como el voto para los militantes no era obligatorio, la jornada transcurrió sin mayor impacto.

El problema principal fue que cada una de las nueve organizaciones políticas solo presentó un binomio en la competencia interna, por lo tanto, el sufragio se 
redujo a consolidar cada candidatura, lo cual se reflejó en la ausencia de debate e incluso en la sensación de inutilidad de estos comicios, vistos por muchos líderes de opinión y, en particular, por los partidos opositores, como un "gasto inútil de recursos".

A tal punto fue resistida esta elección por los opositores que, salvo en el caso del MAs y del MTs, instaron a sus propias militancias a no acudir a las urnas y mandaron delegados para garantizar el único voto que habilitaba la candidatura para las próximas elecciones generales.

Con base en estas consideraciones, esta primera experiencia no fue totalmente exitosa, por ello carece de sentido una lectura seria de los resultados electorales, excepto en el caso del MAs, cuya militancia sí acudió a las urnas. Los resultados, sin embargo, evidencian un gran ausentismo inclusive en este caso, pues solamente acudió a votar el 45,5\% de la militancia inscrita, mientras el promedio de participación de las otras organizaciones fue de alrededor del $6 \%$.

Tabla 2. Resultados electorales por organización política

\begin{tabular}{lrrr}
\hline $\begin{array}{c}\text { Organizaciones } \\
\text { POLÍticas }\end{array}$ & Votos Emitidos & $\begin{array}{c}\text { Habilitados } \\
\text { POR OP }\end{array}$ & $\begin{array}{c}\text { \% DE VOtOS SOBRE } \\
\text { HABILITADOS }\end{array}$ \\
\hline 21F & 18778 & 292490 & 6,4 \\
CC & 4964 & 88122 & 5,6 \\
FPV & 2033 & 31060 & 6,5 \\
MAS-IPSP & 451026 & 991092 & 45,5 \\
MNR & 4871 & 58377 & 8,3 \\
MTS & 6970 & 95391 & 7,3 \\
PAN-BOL & 3480 & 92210 & 3,8 \\
PDC & 1308 & 28717 & 4,6 \\
UCS & 1915 & 38421 & 5,0 \\
Total & 495345 & 1715880 & 28,9 \\
\hline
\end{tabular}

Fuente: elaboración propia con base en datos del oEP

Lo ocurrido en las primarias revela una cartografía electoral difusa, por una parte, debido al declive del partido de gobierno expresado en las diversas encuestas de opinión y en el desgaste natural producto de tres gestiones consecutivas en el poder, aunque, como vimos, se mantiene como la principal fuerza política del sistema; por otra, revela la desarticulación y fragilidad de las alternativas opositoras al actual gobierno y la ausencia de nuevos liderazgos políticos.

Ahora bien, de entre las op opositoras habilitadas para los comicios de octubre próximo, el Movimiento Demócrata Social (MDS) es la organización con mayor vida orgánica y estructura organizativa, aunque es un partido fuertemente 
anclado en la región de Santa Cruz que no ha logrado trascender hacia los demás departamentos del país. La situación de los otros partidos es realmente crítica pues en unos casos se trata de organizaciones nuevas o muy pequeñas, como PAN-BOL, MTS o el FPV, que no tienen mayor presencia, mientras que las cuatro que provienen de siglas históricas como PDC, UCS, FRI y el MNR, han buscado reinventarse para la próxima elección mediante la alianza con candidatos a la presidencia que son externos y totalmente ajenos a la or, pero cuentan con prestigio propio por sus trayectorias políticas, como el expresidente Jaime Paz (1989-1994) con el PDC; Víctor Hugo Cárdenas, militante del MRTKL y ex vicepresidente del Estado durante el primer gobierno de Sánchez de Lozada (1994-1997), ahora con la sigla ucs; Carlos Mesa, ex vicepresidente del segundo gobierno de Sánchez de Lozada (2002-2003), expresidente de Bolivia y vocero de la causa marítima con el FRI; y, por último, el joven activista —no políticode Tarija, integrante de una plataforma ciudadana, que encabeza la lista del MNR, demostrando una vez más la profunda crisis del sistema de representación política.

\section{A MANERA DE CONCLUSIONES}

La coyuntura de 2018 estuvo marcada por un panorama económico estable, aunque en declive y con signos de deterioro hacia el futuro. El partido de gobierno destaca, no obstante, la estabilidad como uno de los principales logros gubernamentales y como emblema hacia las próximas elecciones generales de 2019.

Un aspecto crítico de la democracia boliviana, que se reveló de manera incontrastable durante 2018, es la profunda crisis de institucionalidad reflejada, por una parte, en el escaso o parcial avance de aplicación de la nueva CPE a diez años de su aprobación frente a las grandes expectativas que creó la Asamblea Constituyente hace poco más de una década y, en particular, en la crisis del Órgano Electoral Plurinacional, que responde a dos principales factores: por una parte, a su actuación respecto a los resultados del referendo del 21 de febrero de 2016, que dejó en la ciudadanía la sensación de que no se hizo prevalecer el mandato popular; por otra, a la descomposición interna y el agravamiento de su imagen externa debido a las incongruencias alrededor de la aprobación del proyecto de Ley de Organizaciones Políticas en la Asamblea Legislativa Plurinacional y su posterior aplicación - apresurada- en las elecciones primarias, poniendo a las próximas elecciones generales de octubre en un escenario de gran incertidumbre.

Esta crisis institucional ha puesto en el centro del escenario discursivo, la polarización política entre dos sentidos de la democracia: asociada al respeto a la ley y la institucionalidad y el apego a las reglas de juego, por un lado; y como participación directa de las organizaciones sociales y la justificación histórica 
de un liderazgo hegemónico como oportunidades histórica, única e irrepetible, que apunta a reforzar su legitimación y continuismo en el poder, por otro.

\section{REFERENCIAS}

Molina Diaz, Germán. 2018, 30 de diciembre. "Evaluación de la economía de Bolivia en 2018, proyecciones y perspectivas del 2019." ANF. Recuperado el 17 de febrero de 2019 de https://www.noticiasfides.com/opinion/german-molina-diaz/evaluacion-de-la-economia-de-bolivia-en-2018-proyecciones-y-perspectivas-del-2019

Komadina, Jorge y Celine Geffroy. 2007. El poder del movimiento político. Estrategia, tramas organizativas e identidad del MAS en Cochabamba, 1999-2005. La Paz: CESU, DICYT y PIEB.

Opinión. 2018, 10 de octubre. "García Linera desde Cochabamba dice que se 'vienen nuevas batallas' en Bolivia". Recuperado el 15 de julio de http://www.opinion.com.bo/opinion/articulos/noticias.php?a=2018\&md=1010\&id=269681

Tapia, Luis. 2008. Política salvaje. La Paz: Clacso y Muela del Diablo.

Vásquez, Katiuska. 2018, 7 de octubre. "Más del 90 \% en el eje quieren pasar la página del veredicto de La Haya". Recuperado el 15 de julio de http://www.lostiempos.com/ actualidad/pais / 20181007/mas-del-90-eje-quieren-pasar-pagina-del-veredicto-haya

Zegada, María Teresa. 2017. "Organizaciones sin militancia y los nuevos derroteros de la democracia interna". Revista Andamios 2 (4): pp. 9-16

Zovatto, Daniel. 2006. "Regulación de los partidos en América Latina". Diálogo Político 23 (4): 11-39

Recibido: 1 de abril de 2019

Aceptado: 31 de julio de 2019

María Teresa Zegada Claure. Es doctora en Procesos Sociales y Políticos en América Latina (PROSPAL) por la Universidad de Arte y Ciencias Sociales U-ARCIS, Chile. Investigadora y profesora universitaria. Correo electrónico: zegada_m@yahoo.com 